The International Journal of Engineering and Science (IJES)

|| Volume || 6 || Issue || 5 || Pages || PP 53- 56|| 2017 ||

ISSN (e): $2319-1813$ ISSN (p): $2319-1805$

THE IJES

\title{
The effect of varying span on Design of Medium span Reinforced Concrete T-beam Bridge Deck
}

\author{
Neeraj Kumar \\ Assistant Professor, Department of Civil Engineering, Bipin Tripathi Kumoan Institute of Technology, \\ Dwarahat, Almora, Uttarakhand, India-263653
}

\begin{abstract}
-
Bridge is a structure providing passageway over an obstacle without closing the way beneath. T-beam Bridge is mainly used by designer for small and medium span bridge. Reinforced Concrete is mostly used for highway bridge construction because of its durability, rigidity, economy, ease of construction and ease with pleasing appearance.

This paper describes the design of 4-lane Reinforced Concrete T-beam Bridge deck considering IRC Class-AA tracked loading with span varying from 25 to $40 \mathrm{~m}$. After computing manually and STAAD Pro analysis software, it is observed that dead load bending moment with increasing span increases almost square of span.

Keywords: Bridge, cross girder, longitudinal girder, medium span, Reinforced Concrete Bridge, T-beam Bridge deck.
\end{abstract}

Date of Submission: 20 May 2017

Date of Accepted: 30 May 2017

\section{INTRODUCTION}

A Bridge is a structure providing passage (i.e. a road, railway, canal, pedestrians or pipeline) over an obstacle (i.e. a river, road, rail or valley) without closing the way beneath.

According to the construction material, Superstructure of Bridge are classified as timber, masonry, iron, steel, reinforced concrete, pre-stressed concrete, composite or Aluminum Bridge.

Reinforced concrete is a composite material in compressive load is taken by Concrete and tensile load is taken by Reinforcement or Steel only. Reinforced concrete is well suited for the construction of highway bridges in the medium span range. Reinforced Concrete Bridge is a bridge with reinforced concrete spans and concrete or reinforced-concrete abutments. The types of Reinforced Concrete Bridge are slab bridge, T-beam bridge, hollow girder bridge, balanced cantilever bridge, rigid frame bridge, arch bridge and bow string girder bridge.

In T-beam bridge, the main longitudinal girders are designed as T-beams integral with part of the deck slab, which is cast monolithically with the girders.

Major components of T-beam Bridge

The RC T-beam superstructure consists of the following major components are:

i) Cantilever slab portion: Cantilever slab portion are carries the kerb, handrails, footpath or crash barriers, if provided and a part of the carriageway. The critical section for bending moment is the vertical section at the junction of the cantilever portion and the end longitudinal girder.

ii) Cross girders or diaphragms, intermediate and end ones: Cross girders are provided mostly to stiffen the girders and to reduce torsion in the exterior girders. These are essential over the supports to prevent lateral spread of the girders at the bearings. Another purpose of the cross girders are to balance three deflections of the girders carrying heavy loading with those of the girders with less loading.

iii) Deck slab: Deck slab is the roadway, or the pedestrian walkway, surface of a bridge. Deck slab is one structural element of the superstructure of a bridge. The deck may be constructed of concrete, steel, open grating, or wood. The concrete deck may be an integral part of the bridge structure (T-beam structure) or it may be supported with I-beams or steel girders.

iv) Footpaths: Footpath is a type of thoroughfare that is intended for use only by pedestrians and not other forms of traffic such as motorized vehicles, cycles, and horses.

v) Longitudinal girders, considered in design to be of $\mathbf{T}$-section: Longitudinal girders are provided with straight T-ribs when cross girders are not used. When multiple cross girders are used, the rib is made thinner and the bottom of T-rib is widened to an extent sufficient accommodate the tensile reinforcing bars.

vi) Wearing coat: Wearing coat is provided over concrete bridge decks to protect the structural concrete from the direct wearing effect of the traffic and also to provide cross camber required for the surface drainage. 
The thickness of the wearing coat is kept uniform and the top of the deck is adjusted to facilitate the cross camber for surface drainage.

\section{A. Bridge Description}

\section{METHODOLOGY}

In this paper, all the varying span of 4-lane T-beam bridge deck of span $25 \mathrm{~m}$ to $40 \mathrm{~m}$ are designed with $5 \mathrm{~m}$ increments. The design data for all 4-lane T-beam bridge deck are vehicles live load type: IRC class AA tracked load, thickness of wearing coat $=80 \mathrm{~mm}$, width and depth of kerb $=600 \mathrm{~mm} \times 300 \mathrm{~mm}$. The M30 grade concrete and Fe415 grade High Yield Strength Deformed (HYSD) bars are considered materials for all Reinforced concrete bridges.

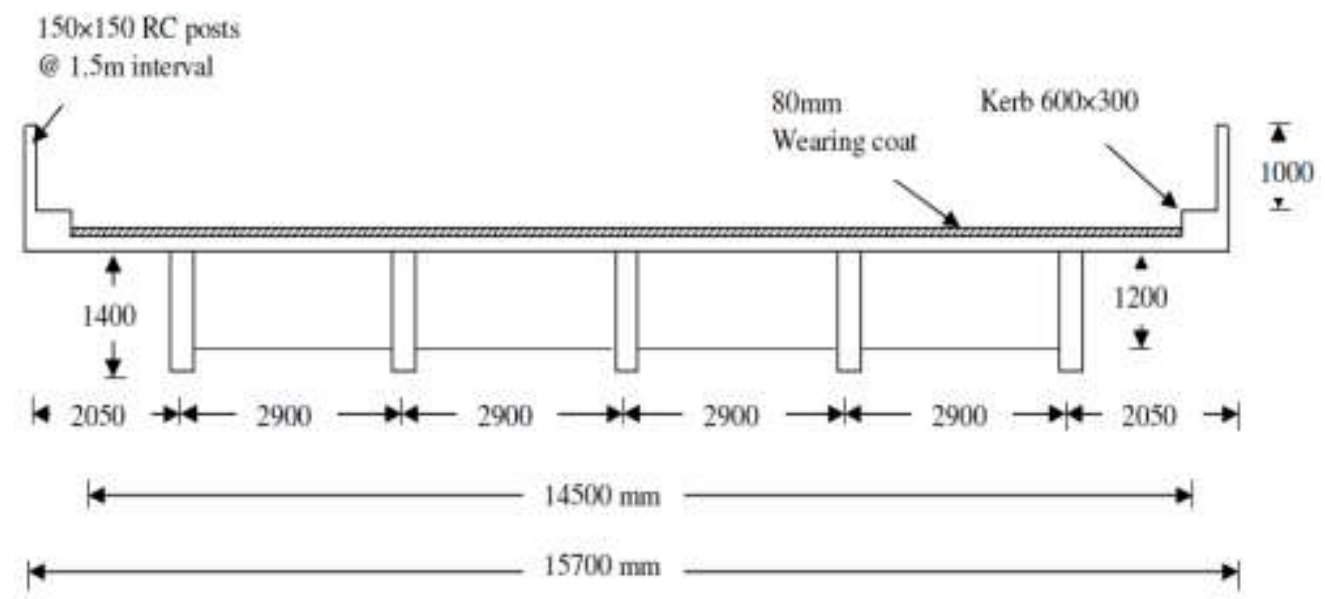

Figure 1: Cross-section of bridge deck

\section{B. Methods}

The design and analyses of all the varying span of 4-lane T-beam bridge deck of span $25 \mathrm{~m}$ to $40 \mathrm{~m}$ are designed with $5 \mathrm{~m}$ increments are done by STAAD.Pro and manually considering as per Indian Standard IS: 456-2000, IRC: 6-2000 and IRC: 21-2000. This conventional method is extensively used with design steps as specified in various text books on bridge engineering (Victor 2007, Krishna Raju 2004, and Rajagopalan 2006).

\section{RESULTS AND DISCUSSION}

In this paper, four cases are considered for design of 4-lane RC T-beam bridge deck with varying span $25 \mathrm{~m}$ to $40 \mathrm{~m}$ with $5 \mathrm{~m}$ increments.

\section{A. Data Summary for RC T-beam bridge deck}

This part explained the data adopted for all the four cases of 4-lane RC T-beam bridges with clear carriageway width of $14.5 \mathrm{~m}$ which is used in the parametric study in STAAD analysis as well as conventional method of design and analysis on design of RC T- beam bridges. For all the four cases of bridges M 30 grade of concrete material and $\mathrm{Fe} 415$ grade of steel are provided.

Table- 1: Summary of data considered for four cases

\begin{tabular}{|c|c|c|c|c|c|c|c|}
\hline $\begin{array}{c}\text { Span } \\
(\mathrm{m})\end{array}$ & $\begin{array}{c}\text { Slab thickness } \\
\mathrm{t}(\mathrm{mm})\end{array}$ & $\begin{array}{c}\text { Overall depth of } \\
\text { Longitudinal Girder } \\
(\mathrm{mm})\end{array}$ & $\begin{array}{c}\text { No. of } \\
\text { L.G. }\end{array}$ & $\begin{array}{c}\text { c/c Distance of } \\
\text { L.G. } \\
(\mathrm{m})\end{array}$ & $\begin{array}{c}\text { Overall depth of } \\
\text { Cross Girder } \\
(\mathrm{mm})\end{array}$ & $\begin{array}{c}\text { No. of } \\
\text { C.G. }\end{array}$ & $\begin{array}{c}\text { c/c Distance } \\
\text { of C.G. }(\mathrm{m})\end{array}$ \\
\hline 25 & 200 & 1600 & 5 & 2.9 & 1400 & 7 & 4.17 \\
\hline 30 & 200 & 2000 & 5 & 2.9 & 1800 & 7 & 5 \\
\hline 35 & 200 & 2200 & 5 & 2.9 & 2000 & 9 & 4.375 \\
\hline 40 & 200 & 2500 & 5 & 2.9 & 2300 & 9 & 5 \\
\hline
\end{tabular}

The above thickness of slab and section for cross girders and longitudinal girders have been adopted after design of the bridge decks using the EXCEL spreadsheet developed in the study. For the above sectional properties, the bridges were analysed in STAAD.Pro and the results obtained are described below. 
B. Summary of data for Design loads

Table-2: Comparison of design Shear force from both the methods

\begin{tabular}{|c|c|c|c|c|c|c|}
\hline \multirow{2}{*}{$\begin{array}{c}\text { Span } \\
(\mathrm{m})\end{array}$} & \multicolumn{3}{|c|}{ STAAD. Pro analysis } & \multicolumn{3}{c|}{ Conventional method of Analysis } \\
\cline { 2 - 7 } & $\begin{array}{c}\text { DLSF } \\
(\mathrm{KN})\end{array}$ & $\begin{array}{c}\text { LLSF } \\
(\mathrm{KN})\end{array}$ & $\begin{array}{c}\text { Total SF } \\
(\mathrm{KN})\end{array}$ & $\begin{array}{c}\text { DLSF } \\
(\mathrm{KN})\end{array}$ & $\begin{array}{c}\text { LLSF } \\
(\mathrm{KN})\end{array}$ & $\begin{array}{c}\text { Total SF } \\
(\mathrm{KN})\end{array}$ \\
\hline 25 & 397.3 & 400.11 & 797.41 & 447.148 & 462 & 909.148 \\
\hline 30 & 530.78 & 421.4 & 952.18 & 527.808 & 467.9741 & 995.7821 \\
\hline 35 & 646.87 & 437.07 & 1083.94 & 608.468 & 472.2414 & 1080.709 \\
\hline 40 & 785.7 & 440.1 & 1225.8 & 689.128 & 475.4418 & 1164.57 \\
\hline
\end{tabular}

The summary results of Design dead load, live load and total load, as obtained from STAAD analysis are presented Table-2. Using the conventional method of design developed as an EXCEL spreadsheet program, the support reactions have also been computed.

\section{Summary of data for bending moment}

The Design bending moments have been obtained from STAAD analysis are presented Table-3. The Bending moments have also been computed using the conventional method of design developed as an EXCEL spreadsheet program are presented in Table-3.

Table-3: Comparison of Bending moment from conventional calculation and STAAD.Pro

\begin{tabular}{|c|c|c|c|c|c|c|}
\hline \multirow{2}{*}{$\begin{array}{c}\text { Span } \\
(\mathrm{m})\end{array}$} & \multicolumn{3}{|c|}{ STAAD. Pro analysis } & \multicolumn{3}{c|}{ Conventional method of Analysis } \\
\cline { 2 - 7 } & DLBM (KN-m) & $\begin{array}{c}\text { LLBM } \\
(\mathrm{KN}-\mathrm{m})\end{array}$ & $\begin{array}{c}\text { Total BM (KN- } \\
\mathrm{m})\end{array}$ & DLBM (KN-m) & $\begin{array}{c}\text { LLBM } \\
(\mathrm{KN}-\mathrm{m})\end{array}$ & $\begin{array}{c}\text { Total BM (KN- } \\
\mathrm{m})\end{array}$ \\
\hline 25 & 2176.1 & 2062 & 4238.1 & 2886.025 & 2310 & 5196.025 \\
\hline 30 & 3513.73 & 2729.25 & 6242.98 & 4068.18 & 2807.845 & 6876.025 \\
\hline 35 & 4834.85 & 3297.32 & 8132.17 & 5451.985 & 3305.69 & 8757.675 \\
\hline 40 & 6762.8 & 3938.1 & 10700.9 & 7037.44 & 3803.534 & 10840.97 \\
\hline
\end{tabular}

\section{The variation of Bending Moment and Shear Force with span}

The variation of dead load SF, live load SF, dead load BM and live load BM are shows as in Figure-2 and Figure-3. It can be found that as the span is increases varying from $25 \mathrm{~m}$ to $40 \mathrm{~m}$ with $5 \mathrm{~m}$ increments, the dead load and live load shear and moment are increases.

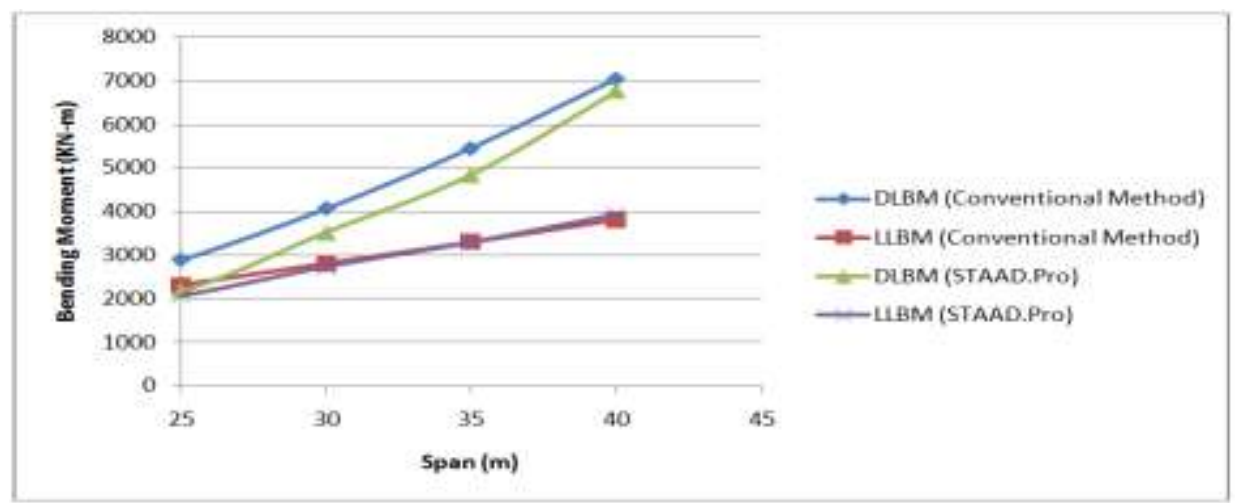

Figure 2: Variation of Bending Moment with Span by STAAD.Pro and Conventional method

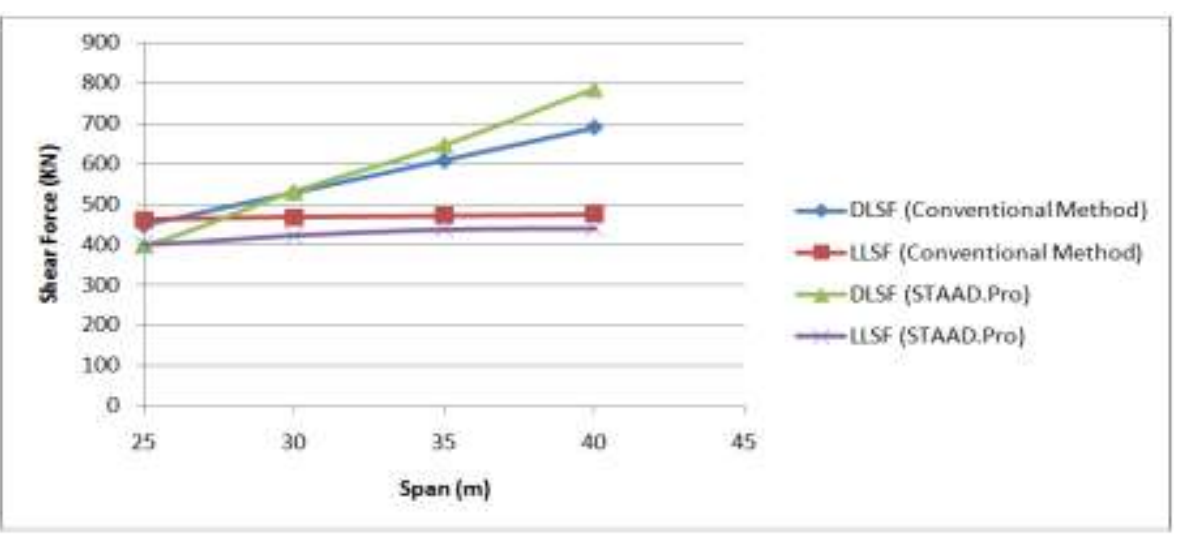

Figure 3: Variation of Shear Force with Span by STAAD.Pro and Conventional method 


\section{CONCLUSION}

In this paper the 4-lane Reinforced Concrete T-beam Bridge deck considering IRC Class-AA tracked loading with span varying from 25 to $40 \mathrm{~m}$ are designed and analyses by manually and STAAD Pro software. After computing the results, following important conclusions are draw from the study:

- With increasing different spans the dead load bending moment increases almost square of the span.

- It is also true that bending moment increases in a parabolic manner with increasing span.

\section{REFERENCES}

[1] IRC: 6-2000, "Standard specifications and code of practice for road bridges: Section II, Loads and Stresses", Indian Roads Congress, 2000, 55pp.

[2] IRC: 21-2000, "Standard specifications and code of practice for road bridges: Section III, Cement concrete (plain and reinforced)", Indian Roads Congress, 2000, 80pp.

[3] IS: 456-2000, "Plain and Reinforced concrete, code of practice: $4^{\text {th }}$ revision", Indian Standard, 2000, 81pp.

[4] Jagdeesh T. R. and Jayaram M. A. (2010), "Design of Bridge Structures", $2^{\text {nd }}$ edition, PHI learning and private limited, New Delhi.

[5] Krisna Raju N. (2004), "Structural Design \& Drawing, Reinforced Concrete and Steel”, $2^{\text {nd }}$ edition, University Press (India) Pvt. Limited, Hyderabad.

[6] Kumar N. and Mandal S. (2015), "The effect of varying span on Design of Short span Reinforced Concrete T-beam Bridge Deck", International Journal of Engineering Research \& Technology (IJERT), ISSN: 2278-0181, Vol. 4, Issue 02, Feb 2015.

[7] Kumar N. (2016), "The effect of varying load on Design of Elastomeric pad bearing", The International Journal of Engineering and Science (The IJES), ISSN(e):2319-1813, ISSN(p): 2319-1805, Volume 5, Issue 1, pp 42-46, Jan 2016.

[8] Punamia B. C., Jain A. K. and Jain A. K. (2011), "R.C.C. Designs (Reinforced Concrete Structures)", 10 ${ }^{\text {th }}$ edition, Laxmi Publication, New Delhi.

[9] Rajagopalan, N. (2006), "Bridge Superstructure”, Narosa Publishing House, New Delhi.

[10] "Standard plans for highway bridges: R.C.C. T-beam and slab superstructures", Ministry of Surface Transport (Roads Wing), New Delhi, 1993, 159 pp.

[11] Taylor F. W., Thompson S. E., and Smulski E. (1955), "Reinforced Concrete Bridges”, John Wiley and Sons, 1955,456 pp.

[12] Victor, D. J. (2007), "Essential of Bridge Engineering", $6^{\text {th }}$ edition, Oxford \& IBH publishing Co. Pvt. Limited, New Delhi. 